\title{
Rancang Bangun Alat Monitoring Ketidakseimbangan Beban Transformator Distribusi Berbasis Internet of Things
}

\author{
Osea Zebua $^{1}$, Endah Komalasari ${ }^{2}$, Syaiful Alam ${ }^{3}$, Aldiansyah ${ }^{4}$ \\ Jurusan Teknik Elektro, Universitas Lampung, Bandar Lampung \\ J1. Prof. Sumantri Brojonegoro No.1 Bandar Lampung 35145 \\ 1osea.zebuadeng.unila.ac.id \\ ${ }^{2}$ endah.komalasari@eng.unila.ac.id \\ ${ }^{3}$ syaiful.alameeng.unila.ac.id \\ ${ }^{4}$ aldi.kicuy@gmail.com
}

Intisari - Kerusakan transformator distribusi sering disebabkan oleh ketidakseimbangan beban, sehingga monitoring ketidakseimbangan beban transfornator distribusi perlu dilakukan. Letak dan lokasi transformator distribusi yang jauh dan tersebar mengharuskan monitoring harus dilakukan dari jarak jauh. Teknologi internet of things (IoT) dan komunikasi tanpa kabel mendukung monitoring dari jarak jauh. Makalah ini menyajikan perancangan dan pembuatan alat monitoring ketidakseimbangan beban transformator distribusi menggunakan teknologi IoT. Mikrokontroler Arduino digunakan untuk memproses data tegangan dan arus dari sensor, menghitung indikator ketidakseimbangan beban dan mengirim data hasil proses ke jaringan internet menggunakan Ethernet shield dan router yang diperlengkapi dengan modem. Thingspeak digunakan sebagai platform IoT. Hasil pengujian menunjukkan bahwa peralatan monitoring mampu bekerja dengan baik sehingga kondisi ketidakseimbangan beban transformator distribusi dapat dimonitor secara online dari jarak jauh menggunakan perangkat yang terhubung ke jaringan internet.

Kata kunci - Monitoring, Ketidakseimbangan Beban, Transformator Distribusi, Internet of things.

Abstract - Damage to the distribution transformer is often caused by unbalanced load, so it is necessary to monitor the unbalanced load condition of the distribution transformer. The remote and dispersed location of distribution transformers requires remote monitoring. Internet of things (IoT) technology and wireless communication support remote monitoring. This paper presents the design and manufacture of distribution transformer unbalanced load monitoring tools using IoT technology. The Arduino microcontroller is used to process voltage and current data from sensors, calculate unbalanced load indicators and send process data to the internet network using an Ethernet shield and a router equipped with a modem. Thingspeak is used as an IoT platform. The test results show that the monitoring equipment can work properly so that the distribution transformer unbalanced load conditions can be monitored online remotely using a device connected to the internet network.

Keywords - Monitoring, Unbalanced Load, Distribution Transformer, Internet of Things.

\section{PENDAHULUAN}

Transformator distribusi merupakan peralatan listrik yang sangat penting dalam penyaluran dan pendistribusian energi listrik ke konsumen listrik. Tranformator distribusi mengubah energi listrik dari jaringan tegangan menengah ke jaringan tegangan rendah. Transformator distribusi dalam sistem jaringan distribusi jumlahnya sangat banyak dan letaknya tersebar serta jauh dari pusat kontrol.

Kerusakan transformator distribusi menyebabkan energi listrik tidak dapat tersalurkan. Berbagai hal menjadi penyebab kerusakan transformator distribusi dalam operasinya, namun ketidakseimbangan beban dan pembebanan berlebih menyumbang $45 \%$ dari penyebab kerusakan (Salustiano dkk. 2013) Pembebanan berlebih dapat diantisipasi dengan cepat oleh alat proteksi yang terdapat pada transformator, namun ketidakseimbangan beban tidak. Bebanbeban listrik yang terhubung besarnya tidak sama pada setiap fasa mengakibatkan arus listrik yang mengalir besarnya tidak sama pada setiap fasa. Arus yang besarnya tidak sama ini membuat rugi-rugi tembaga semakin besar dibandingkan bila arus yang mengalir sama besar. Selain itu, ketidakseimbangan beban juga 
mengakibatkan arus listrik akan mengalir pada fasa atau konduktor netral.

Rugi-rugi tembaga ini terjadi dalam bentuk panas dan menaikkan temperatur isolasi dari konduktor. Bila kondisi ketidakseimbangan beban berlangsung terus-menerus, kemungkinan temperatur akan menurunkan kinerja isolasi dan dapat menyebabkan terjadinya hubung-singkat antar konduktor yang kemudian dapat mengakibatkan kegagalan transformator distribusi.

Monitoring ketidakseimbangan beban menjadi hal yang penting bagi kontinuitas operasi transformator distribusi. Monitoring jarak jauh harus dilakukan karena letak transformator yang umumnya tersebar dan jauh dari pusat kontrol. Teknologi internet of things (IoT) mendukung kebutuhan monitoring dari jarak jauh dan selain itu teknologi IoT ini dapat menyimpan data hasil monitoring untuk ditampilkan dan dianalisis secara online (Wang dkk. 2013).

Beberapa penelitian telah dibuat untuk memonitor kondisi "kesehatan" dari transformator distribusi dengan menggunakan teknologi IoT (Yaman dan Bicen, 2019; Pawar dan Deosarkar, 2017; Vaz 2018), namun tidak secara khusus memonitor kondisi ketidakseimbangan beban.

Makalah ini menyajikan peracangan dan pembuatan alat monitoring ketidakseimbangan beban transformastor distribusi menggunakan teknologi internet of things. Mikrokontroler digunakan sebagai alat pemrosesan data yang diperoleh dari sensor tegangan dan sensor arus, menghitung indikator ketidakseimbangan dan rugi-rugi tembaga, dan mengirim data hasil proses ke webserver dari platform IoT di jaringan internet melalui Ethernet shield dan router yang diperlengkapi dengan modem internet.

\section{KETIDAKSEIMBANGAN BEBAN TRANSFORMATOR DISTRIBUSI}

Ketidakseimbangan beban adalah kondisi dimana beban-beban listrik yang terhubung pada setiap fasa transformator distribusi besarnya tidak sama. Salah satu indikator yang digunakan untuk mengukur letidakseimbangan beban adalah menggunakan nilai rms arus fasa (Zebua dkk, 2016) dan dapat dirumuskan dengan:

$I_{U N}=\frac{\left|I_{R}-I_{\text {avg }}\right|+\left|I_{S}-I_{\text {avg }}\right|+\left|I_{T}-I_{\text {avg }}\right|}{I_{\text {avg }}} \times 100 \%$

dimana $I_{\text {avg }}$ adalah nilai arus rata-rata yang besarnya:

$I_{\text {avg }}=\frac{I_{R}+I_{S}+I_{T}}{3}$

dan $I_{R}, I_{S}$ dan $I_{T}$ masing-masing nilai rms dari fasa $\mathrm{R}$, fasa $\mathrm{S}$ dan fasa $\mathrm{T}$.

Bila faktor ketidakseimbangan beban setiap fasa dinyatakan dengan perbandingan antara arus setiap fasa terhadap arus rata-rata, maka faktor ketidakseimbangan beban fasa $R$, fasa $\mathrm{S}$ dan fasa $\mathrm{T}$ masing-masing dapat dirumuskan dengan:

$$
\begin{aligned}
& a=\frac{I_{R}}{I_{a v g}} \\
& b=\frac{I_{S}}{I_{a v g}} \\
& c=\frac{I_{T}}{I_{a v g}}
\end{aligned}
$$

Persamaan 1 dapat dituliskan kembali menjadi:

$I_{U N}=\frac{|a-1|+|b-1|+|c-1|}{3} \times 100 \%$

Ketidakseimbangan beban juga berpengaruh pada ketidakseimbangan tegangan. Dengan menggunakan nilai rms tegangan fasa, maka indikator ketidakseimbangan tegangan dapat dirumuskan dengan (von Jouanne dan Banerjee, 2001; Pillay dan Manyage, 2001; Seiphetlho dan Rens, 2010):

$$
V_{U N}=\frac{\left|V_{R}-V_{a v g}\right|+\left|V_{S}-V_{a v g}\right|+\left|V_{T}-V_{a v g}\right|}{V_{a v g}} \times 100 \%
$$


dimana,

$$
V_{\text {avg }}=\frac{V_{R}+V_{S}+V_{T}}{3}
$$

dan $I_{R}, I_{S}$ dan $I_{T}$ masing-masing adalah nilai rms tegangan fasa ke netral dari fasa $\mathrm{R}$, fasa $S$ dan fasa $T$.

Faktor ketidakseimbangan tegangan dari fasa $R$, fasa $S$ dan fasa $T$ masing-masing dirumuskan dengan persamaan 9, 10 dan 11:

$$
\begin{aligned}
& d=\frac{V_{R}}{V_{a v g}} \\
& e=\frac{V_{S}}{V_{a v g}} \\
& f=\frac{V_{T}}{V_{a v g}}
\end{aligned}
$$

Sehingga persamaan 7 dapat ditulis menjadi:

$$
V_{U N}=\frac{|d-1|+|e-1|+|f-1|}{3} \times 100 \%
$$

Nilai arus yang mengalir pada konduktor netral dapat dihitung dengan menggunakan rumusan (Rao dkk, 2013):

$$
I_{N}=I_{a v g} \times\left(a-\frac{(b+c)}{2}+j \frac{(c-b)}{2} \sqrt{3}\right)
$$

Rugi-rugi tembaga pada kondisi tidak seimbang, $P_{\text {Culoss }}$, dapat dihitung dengan rumusan:

$$
P_{\text {Culoss }}=I_{R}^{2} R_{02}+I_{S}^{2} R_{02}+I_{T}^{2} R_{02}
$$

$R_{02}$ adalah resistansi ekivalen per fasa transformator ditinjau dari sisi sekunder yang besarnya dapat dihitung dengan: persamaan (Theraja dan Theraja, 2005):

$R_{02}=\frac{P_{\text {Culoss }, F L}}{3 \times I_{2}^{2}}$

dan,

$$
I_{2}=\frac{S}{\sqrt{3} \times V_{S}}
$$

dimana $P_{\text {Culoss } F L}$ adalah rugi-rugi tembaga pada beban penuh, $S$ adalah kapasitas transformator dan $V_{S}$ adalah tegangan sisi sekunder.

Rugi-rugi total dari transformator distribusi pada kondisi tidak seimbang adalah:

$$
P_{\text {totloss }}=P_{\text {NLloss }}+P_{\text {Culoss }}
$$

dimana $P_{N L l o s s}$ adalah rugi-rugi tanpa beban.

\section{METODE}

\section{A. Perancangan dan Pembuatan Alat Monitoring}

Alat monitoring ketidakseimbangan beban transformator distribusi dirancang dan dibuat berdasarkan atas diagram gambar 1. Sensor tegangan ZMPT101B digunakan untuk mengukur besar tegangan rms setiap fasa. Sensor arus SCT019 digunakan untuk mengukur besar arus rms setiap fasa. Mikrokontroler Arduino Mega digunakan untuk memproses nilai tegangan dan arus dari sensor, kemudian menghitung indikator ketidakseimbangan beban, besar arus pada fasa netral dan besaran-besaran lainnya. Nilai-nilai yang diperoleh kemudian dikirim ke jaringan internet menggunakan Ethernet shield W5100 dan router TP-Link dengan modem internet.

Seluruh pemrograman untuk menghitung nilai rms tegangan dan arus fasa, perhitungan indikator ketidakseimbangan beban dan tegangan, arus netral dan rugi-rugi tembaga serta pengiriman data hasil perhitungan ke platform IoT di jaringan internet menggunakan bahasa pemrograman $\mathrm{C}$ (Kadir, 2013). Platform IoT Thingspeak digunakan sebagai tempat penyimpanan data yang dikirim dan menampilkan data secara online (Mathwork, 2016).

\section{B. Pengujian}

Pengujian dilakukan pada sisi tegangan rendah dari transformator distribusi, yakni pada panel hubung bagi transfomator (PHBT). Spesifikasi transformator distribusi yang diuji adalah kapasitas 160kVA, 20/0,4 $\mathrm{kV}$, DYn5, rugi-rugi tanpa beban adalah $400 \mathrm{~W}$, rugi-rugi pada beban penuh adalah 
2000W dan tegangan impedansi adalah sebesar 4\%. Pengujian dilakukan selama kurang lebih satu jam. Set-up rangkaian pengujian ditunjukkan pada gambar 2 .

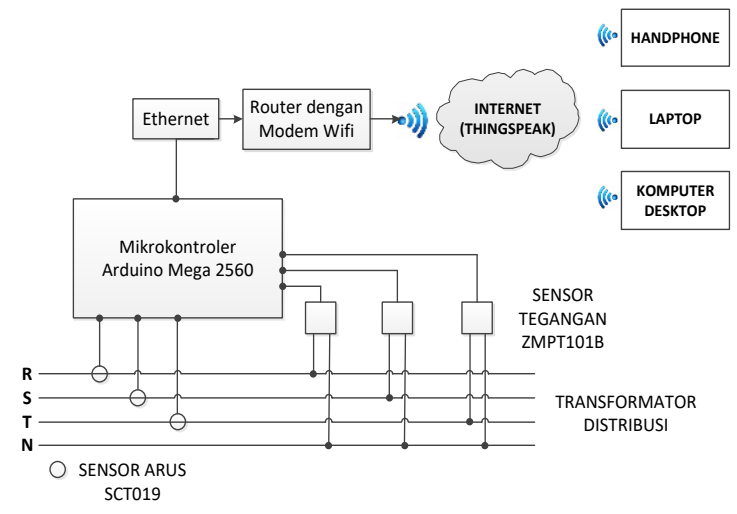

Gbr.1 Diagram perancangan alat monitoring ketidakseimbangan beban transformator distribusi

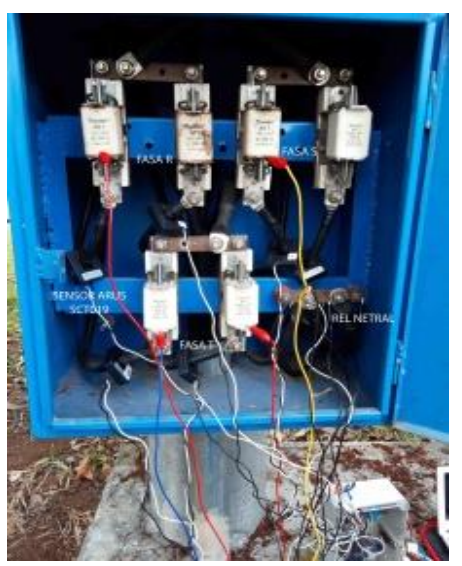

Gbr.2 Set-up Rangkaian Pengujian.

\section{HASIL DAN PEMBAHASAN}

Alat monitoring ketidakseimbangan beban transformator hasil perancangan ditunjukkan pada gambar 3 .

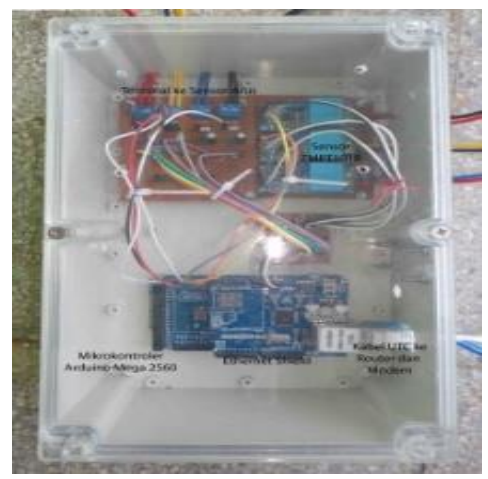

Gbr.3 Bentuk fisik alat monitoring ketidakseimbangan transformator distribusi.
Data hasil pengukuran dan perhitungan ditampilkan pada laman dari platform IoT Thingspeak. Nilai rms tegangan setiap fasa ditunjukkan pada gambar 4, gambar 5 dan gambar 6. Sementara hasil pengujian nilai arus setiap fasa ditunjukkan pada gambar 7, gambar 8 dan gambar 9 .

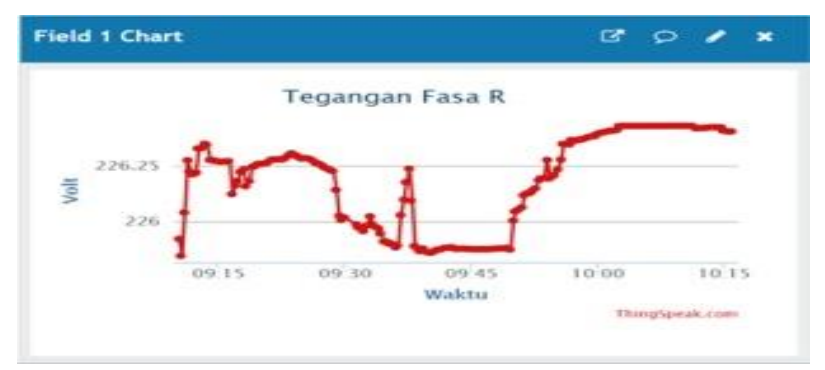

Gbr. 4 Tegangan Fasa R

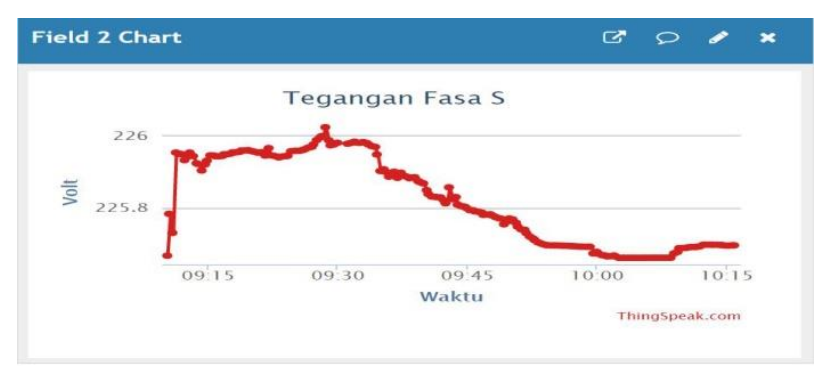

Gbr.5 Tegangan Fasa S

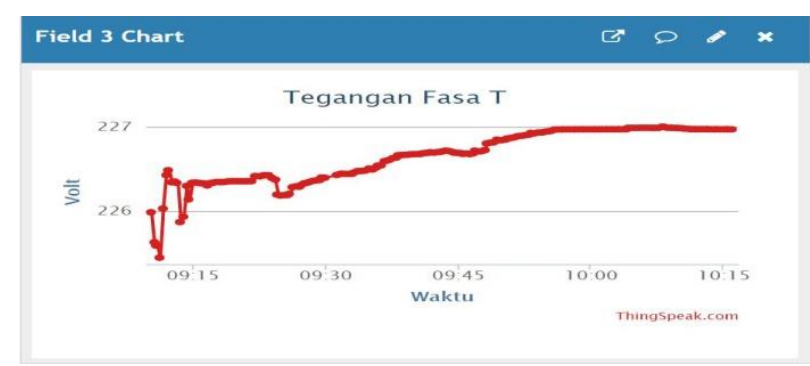

Gbr.6 Tegangan Fasa T

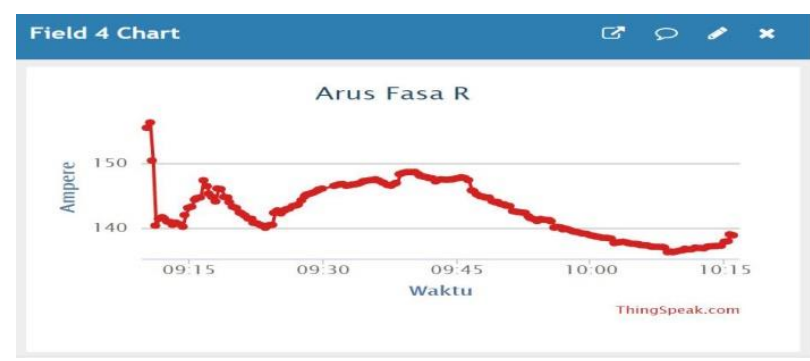

Gbr.7 Arus Fasa R

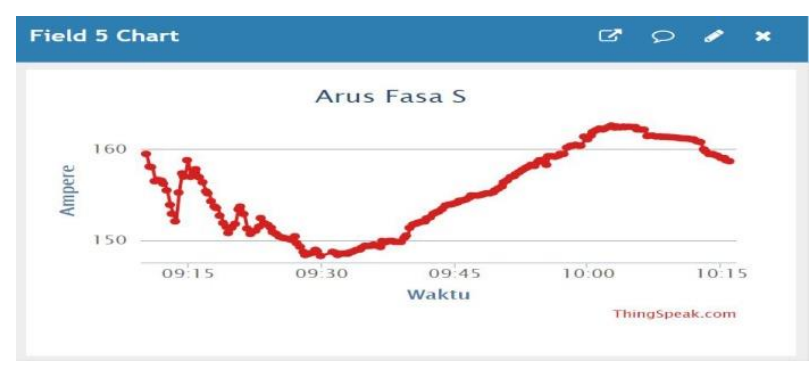

Gbr.8 Arus Fasa S 


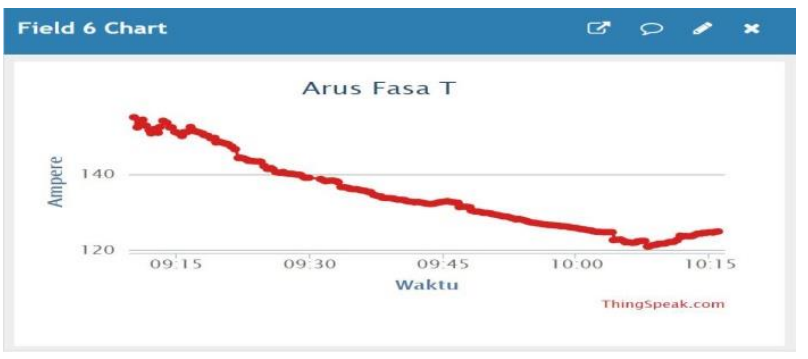

Gbr.9 Arus Fasa T

Indikator ketidakseimbangan beban dan ketidakseimbangan tegangan selama pengujian ditunjukkan pada gambar 10 dan gambar 11.

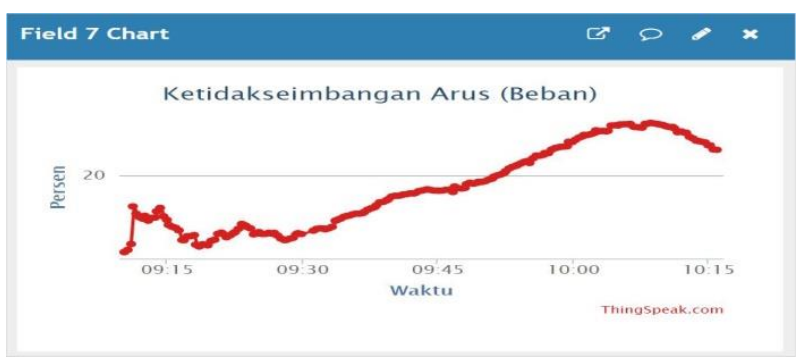

Gbr.10 Ketidakseimbangan Beban

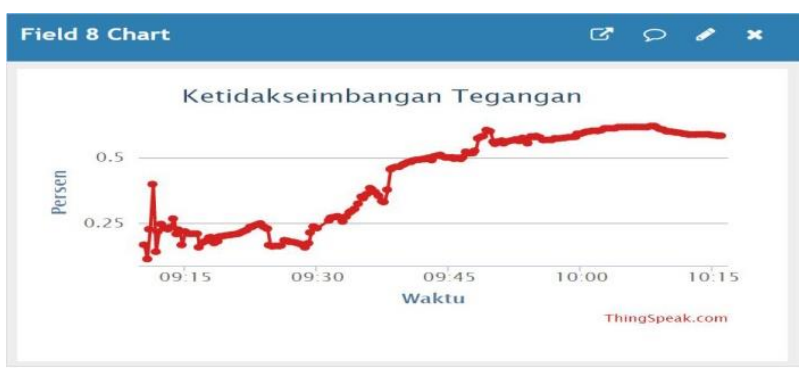

Gbr.11 Ketidakseimbangan Tegangan

Gambar 4 hingga gambar 9 menunjukkan bahwa hubungan arus dan tegangan berbanding terbalik, dimana semakin besar arus fasa, semakin kecil nilai tegangan fasa. Sementara penurunan yang tajam pada nilai arus pada fasa $\mathrm{T}$ semakin memperbesar persentase ketidakseimbangan beban dan ketidakseimbangan tegangan.

Dari gambar 10 dan gambar 11, selama pengujian persentase ketidakseimbangan beban maksimum adalah sebesar $31,11 \%$ dengan persentase ketidakseimbangan tegangan maksimum adalah kurang dari $0,62 \%$. Batas toleransi dari persentase ketidakseimbangan tegangan untuk mesinmesin listrik adalah sebesar 2\% (von Jouanne dan Banerjee, 2001).

Asumsi batas toleransi yang sama digunakan juga untuk batas toleransi ketidakseimbangan tegangan dari transformator distribusi karena transformator distribusi mensuplai energi listrik untuk mesin-mesin listrik.

Besar arus pada fasa netral dan rugi-rugi total juga ditampilkan secara online pada laman Thingspeak, seperti ditunjukkan pada gambar 12 dan gambar 13.

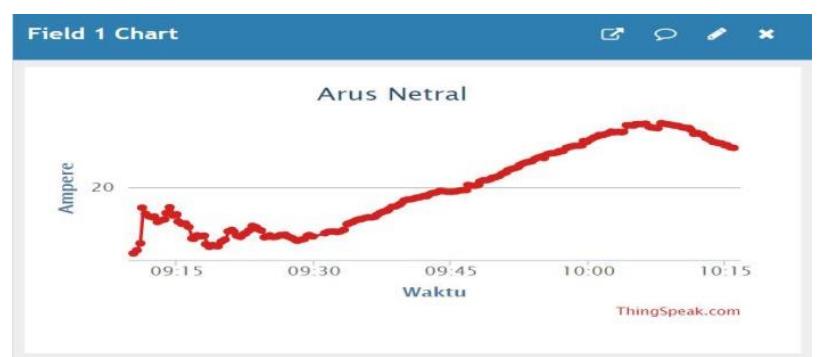

Gbr.12 Arus Fasa Netral

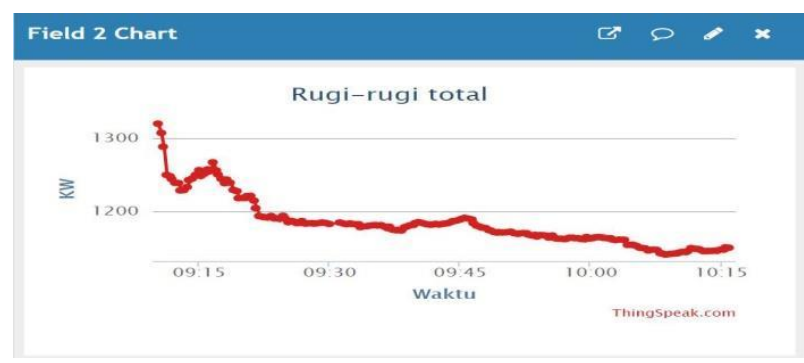

Gbr.13 Rugi-rugi total

Gambar 13 menunjukkan bahwa arus fasa netral semakin besar bila persentase ketidakseimbangan beban semakin besar. Hal ini sesuai dengan persamaan 13 .

Perbandingan rugi-rugi tembaga pada kondisi tidak seimbang dibandingkan dengan rugi-rugi tembaga pada kondisi seimbang ditunjukkan pada gambar 14. Rugi-rugi pada kondisi seimbang $P_{\text {Culossb }}$, dihitung dengan persamaan:

$P_{\text {Culossb }}=3 I_{\text {avg }}^{2} R_{02}$

dimana besar nilai $R_{02}$ diperoleh dari persamaan 15 dan persamaan 16 , yakni besar arus fasa pada sisi sekunder adalah:

$I_{2}=\frac{S}{\sqrt{3} \times V_{S}}=\frac{160.10^{3}}{\sqrt{3} \times 0,4.10^{3}}=230,94 \mathrm{~A}$

dan resistansi per fasa ditinjau dari sisi sekunder menjadi:

$R_{02}=\frac{P_{\text {Culoss }, F L}}{3 \times I_{2}^{2}}=\frac{1600}{3 \times 230,94^{2}}=0,01 \mathrm{ohm} /$ fasa 


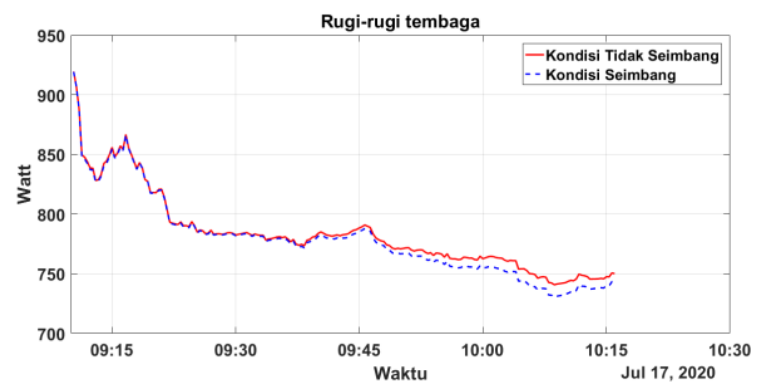

Gbr.14 Perbandingan rugi-rugi tembaga pada kondisi beban seimbang dan beban tidak seimbang.

Gambar 14 menunjukkan bahwa pada kondisi persentase ketidakseimbangan beban yang besar, maka rugi-rugi tembaga akan semakin besar.

Faktor ketidakseimbangan arus dan tegangan masing-masing ditunjukkan pada gambar 15 dan gambar 16. Dari kedua gambar terlihat bahwa nilai faktor ketidakseimbangan arus lebih besar dari nilai faktor ketidakseimbangan tegangan yang mengindikasikan bawa persentase ketidakseimbangan arus (beban) jauh lebih besar dari persentase ketidakseimbangan tegangan. Selama waktu pengujian antara pukul 09.45 sampai dengan pukul 10.00, faktor ketidakseimbangan tegangan dan arus pada fasa $\mathrm{S}$ dan fasa $\mathrm{T}$ menjauhi nilai 1 , sehingga memperbesar persentase ketidakseimbangan beban (arus) dan persentase ketidakseimbangan tegangan pada rentang waktu tersebut. Hal ini sesuai dengan persamaan 6 dan persamaan 12 .

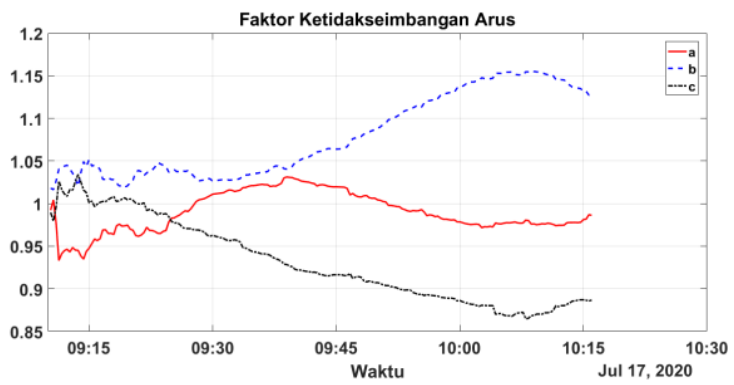

Gbr.15 Faktor Ketidakseimbangan Arus

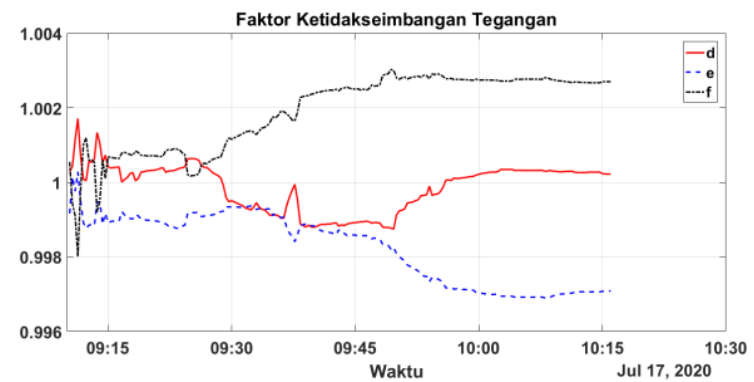

Gbr.16 Faktor Ketidakseimbangan Tegangan

\section{PENUTUP}

Alat monitoring ketidakseimbangan beban mampu bekerja dengan baik untuk mengirimkan data ketidakseimbangan beban transformator distribusi dan data pengukuran dan perhitungan lainnya ke laman platform internet of things, sehingga dapat dimonitor dari jarak jauh secara online melalui perangkat yang terhubung dengan jaringan internet.

Indikator ketidakseimbangan beban menggunakan nilai arus fasa dapat menggambarkan dengan baik kondisi transformator distribusi pada keadaan beban tidak seimbang.

\section{UCAPAN TERIMA KASIH}

Ucapan terima kasih diucapkan kepada Lembaga Penelitian dan Pengabdian Kepada Masyarakat Universitas Lampung yang telah memberikan dana untuk terlaksananya Penelitian Dasar dengan Surat Perjanjian Kontrak nomor 1338/UN26.21/PN/2020.

\section{REFERENSI}

[1] Salustiano, R., Neto, E., Martinez, M. (2013) The Unbalanced Load Cost on Transformer Losses at A Distribution System, 22 $2^{\text {nd }}$ International Conference and Exhibition on Electricity Distribution, pp.1-3.

[2] Wang, C., Daneshmand, M., Dohler, M., Mao, X., Hu, R.Q., Wang, H. (2013) Guest Editorial - Special Issues on Internet of Things (IoT): Architecture, Protocols and Services. IEEE Sensors Journal, 13, 10, 3505-3508.

[3] Yaman, O., Bicen, Y. (2019) An Internet of Things (IoT) Based Monitoring System for Oil-immersed Transformer. Balkan Journal of Electrical and Computer Engineering, 7, 3, 226-234.

[4] Pawar, R.R., Deosarkar, S.B. (2017) Health Condition Monitoring System For Distribution Transformer Using Internet of Things. Proceedings of the IEEE 2017 International Conference on Computing Methodologies and Communication, 117122.

[5] Vaz, F.A.J. (2018). IoT Based Distribution Transformer Care System. Proceedings of $4^{\text {th }}$ International Conference on Energy 
Efficient Technologies for Sustainability (ICEETS), 1-6.

[6] von Jouanne, A., Banerjee, B. (2001) Assessment of Voltage Unbalance. IEEE Transaction on Power Delivery, 16, 4, 782790.

[7] Pillay, P., Manyage M. (2001) Defenition of Voltage Unbalance. IEEE Power Engineering Review, 21, 5, 49-51

[8] Seiphetlho, T.E., Rens, A.P.J. (2010) On the Assesment of Voltage Unbalance. Proceedings of $14^{\text {th }}$ International Conference on Harmonic and Quality of Power (ICHQP), 1-6.

[9] Rao, N.M., Narayanan, R., Vausdevamurthy, B.R., Das, S.K. (2013) Performance
Requirements of Present-Day Distribution Transformer. IEEE ISGT Asia 2013, 1-6.

[10] Zebua, O., dkk. (2016) Rancang Bangun Alat Monitoring Ketidakseimbangan Beban Pada Jaringan Tegangan Menengah. Jurnal Nasional Teknik Elektro, 5, 3, 405-413.

[11] Theraja, B.L., Theraja, A.K. (2005) A Textbook of Electrical Technology, Volume II: $A C$ and DC Machines. S. Chand and Co.Ltd, New Delhi.

[12] Kadir, A. (2013) Pemrograman Mikrokontroler Arduino dan Aplikasinya. Penerbit Andi, Yogyakarta.

[13] Mathwork Inc. (2016) Thingspeak: OpenSource Internet of Things. 